\title{
A cultura como campo de inovações organizacionais
}

Lucia Lippi Oliveira*

\section{Resumo}

0 artigo analisa a atuação dos governos militares no campo das políticas de cultura. A criação do Conselho Federal de Cultura (CFC) em 1966 foi uma das primeiras iniciativas. Nos anos 1970 um processo de modernização começa a se desenhar com o Programa de Ação Cultural $(P A C)$, que vai dar origem à Fundação Nacional de Arte (Funarte). Tais experiências de gestão acontecem quando a cultura ainda fazia parte do Ministério da Educação. 0 Programa das Cidades Históricas (PCH), originalmente ligado à Seplan, e que atuou no campo do patrimônio sobretudo no Nordeste, merecerá destaque, já que inovou ao lançar mão de procedimentos de gestão inéditos na burocracia estatal. As transformações das práticas burocráticas e organizacionais - Institutos, Secretarias e Subsecretarias Fundações - marcam as experiências de modernização da cultura e apontam as batalhas travadas no campo das políticas de cultura implementadas nos tempos da ditadura e no primeiro governo eleito democraticamente.

\section{Palavras-chave}

Políticas de cultura. Governos militares. Modernização organizacional.

\section{Abstract}

This paper analyzes the role of military governments in the field of cultural policy. The creation of the Federal Council of Culture (Conselho Federal de Cultura or CFC) in 1966 was one of the first initiatives. In the 1970s, a process of modernization began to take shape with the creation of the Cultural Action Program (Programa de Ação Cultural or PAC) which would later give birth to the National Art Foundation (Funarte). These management experiences happened when culture was still an issue that belonged to the Ministry of Education. The Historical Cities Program (Programa das Cidades Históricas or PCH), originally connected to Seplan, and which has served in the field of heritage especially in Brazil's northeast region deserves prominence since it has innovated by making use of unprecedented management procedures in State bureaucracy. The transformations of bureaucratic and organizational practices - Institutes, Departments and

\footnotetext{
* Doutora em Sociologia pela Universidade de São Paulo (USP); e pesquisadora e professora do Centro de Pesquisa e Documentação de História Contemporânea do Brasil (CPDOC) da Fundação Getúlio Vargas (FGV). E-mail: lucia.lippi@fgv.br.
} 
Secretariats, as well as Foundations - mark experiences of culture modernization and show the battles waged in the field of cultural policies implemented in times of the dictatorship and during the first democratically elected government.

\section{Keywords}

Cultural policies. Military governments. Organizational Modernization.

\section{Introdução}

Nos anos 1960 a esquerda via o Estado como vértice, como motor do desenvolvimento das forças históricas. A questão nacional assumia o centro da luta político-ideológica então em curso, e o Estado, reificação do bem público, era o eixo central, a partir do qual seria possível operar a ruptura com o passado. Entretanto, o Estado brasileiro foi tomado pelas forças da direita, que passaram a implementar políticas para sua modernização, o que desafiava o esquema interpretativo original das esquerdas que pressupunha ser a direita a guardiã do passado. Para uns, o golpe de Estado se esgotaria em breve e voltaríamos à contínua luta para galgar espaços no aparelho de Estado. Para outros, era preciso mostrar os limites e a coerção daquele Estado. O período 1964-1968 concentra atividades e práticas de enfrentamento entre as forças de esquerda que queriam ocupar os nichos do Estado e seus novos ocupantes.

Adeflagraçãodogolpe, amemóriadaatuaçãodaditadurae,principalmente, a dos "anos de chumbo", vem sendo recuperada por inúmeros depoimentos, livros, filmes. Trabalhar com outros ângulos de ação do governo que não o da repressão, ao contrário, tem sido menos frequentado. Queremos retornar ao tema e acompanhar como foi tomando forma um novo desenho de gestão no campo da política cultural na segunda metade dos anos 1970, quando a cultura ainda fazia parte do Ministério da Educação.

O presente texto foi originalmente apresentado na mesa redonda: "Políticas culturais nos governos autoritários" realizada a 4 de agosto de 2005, no âmbito do Projeto Pronex: Direitos e cidadania, do CPDOC/FGV. E ficou lá parado no tempo. As recentes análises sobre os 50 anos da ditadura e, principalmente, o livro de Rodrigo Patto, As universidades e o regime militar (MOTTA, 2014), reascenderam um possível interesse em tentar destrinchar 
os meandros, as tentativas, os ensaios e os erros no campo da política cultural do Estado brasileiro naqueles anos.

\section{As primeiras análises}

Os primeiros textos de análise acadêmica sobre o mundo da cultura do período autoritário estão presentes no livro, organizado por Sérgio Miceli, Estado e Cultura no Brasil (1984), resultado de seminário sob o mesmo título promovido no segundo semestre de 1982 pelo Instituto de Estudos Econômicos, Sociais e Políticos de São Paulo (IDESP) em convênio com a Funarte, e no artigo de Renato Ortiz, "Estado autoritário \& cultura" publicado no livro Cultura brasileira \& identidade nacional (1985). Esses dois textos ofereceram os primeiros e principais pontos a partir dos quais se pode avançar nas futuras pesquisas.

$\mathrm{O}$ artigo de Miceli "O processo de 'construção institucional' na área cultural federal (anos 70)" trata da dinamização do Instituto Nacional do Livro (INL) - sua ampliação para o setor do livro didático e coedição com editoras particulares - e da criação do Programa de Ação Cultural (PAC), lançado em agosto de 1973, iniciativas que marcam a gestão de Jarbas Passarinho, ministro da Educação do governo Médici (1969/1973). O PAC é apresentado como programa com novo estilo de gestão, que funcionou a partir de núcleos e grupos-tarefas, dispondo de recursos do FNDE, com quadros de fora da carreira do MEC e sendo capaz de atrair profissionais de sucesso oriundos de diferentes instituições. Assim, se é possível reconhecer novos estilos de gestão no campo da ação cultural, tal atuação do Estado nos anos 1970, segundo o autor, se concentrava em áreas de mercado diminuto e de produção artesanal personalizada.

Sérgio Miceli acompanha também a estrutura organizacional do Ministério da Educação e Cultura nas gestões Ney Braga, Eduardo Portella e Rubem Ludwig. Sintetiza suas observações ao sinalizar a presença de um conflito entre a "vertente executiva" e a "patrimonial" no processo de construção institucional da política cultural. Em outro artigo do mesmo livro, "Teoria e prática da política cultural oficial no Brasil” (p. 97-112), Miceli vai destacar as alterações introduzidas no campo da cultura, principalmente da cultura popular, na gestão de Eduardo Portela, visíveis em documentos de autoria de Márcio Tavares d'Amaral, Secretário de Assuntos Culturais e de Pedro Demo. 
Gabriel Cohn também publica no mesmo livro. Seu artigo "A concepção oficial da política cultural nos anos 70" (p.87-96) compara dois documentos: "Diretrizes para uma Política Nacional de Cultura", na gestão de Jarbas Passarinho, e "Política Nacional de Cultura", na gestão de Ney Braga.

Já Renato Ortiz, no artigo "Estado autoritário \& cultura”, que integra o livro Cultura brasileira \& identidade nacional, de 1985 (p. 79-126), procura examinar de que modo as relações entre cultura e Estado se alteram no pós-64, quando há expansão de bens culturais (produção, distribuição e consumo) e criação de grandes conglomerados (TV Globo, Editora Abril). O autor enfatiza a criação do mercado de bens culturais com volume e dimensão nacionais e indica a questão da integração, ou melhor, da falta de integração como o problema maior a ser enfrentado pelo discurso ideológico da Segurança Nacional, que vai perseguir a integração das diversas regiões brasileiras no interior da hegemonia estatal.

Segundo Ortiz, passa a valer uma divisão de trabalho entre cultura de massa deixada a empresas privadas, e cultura artística e popular sob o encargo do governo. Sua análise vai tomar como foco inicial o Conselho Federal de Cultura (CFC), criado no governo Castelo Branco com o objetivo de elaborar uma nova política de cultura para o país. Mas isto não acontece. Vejamos como o autor desenvolve seu argumento. O Conselho congrega intelectuais tradicionais originários do Instituto Histórico e Geográfico Brasileiro (IHGB) e da Academia Brasileira de Letras (ABL), como Josué Montello, Adonias Filho, Augusto Meyer, Murilo Miranda, Rodrigo Melo Franco de Andrade, Américo Jacobina Lacombe, entre outros. Ortiz examina o pensamento do CFC pela leitura dos artigos presentes na Revista Cultura, porta-voz oficial do Conselho, no Boletim, e na Revista Brasileira de Cultura, todas editadas pelo Ministério da Educação e Cultura (MEC). Para esses intelectuais, a cultura brasileira é compreendida e apresentada como "unidade na diversidade" e a tradição (entendida como ontologia do SER brasileiro) é objetivada em patrimônios representados pelos grandes nomes e pelo folclore. Para tais intelectuais, 1964 representava uma continuidade e não uma ruptura e a prioridade da política cultural, portanto deveria continuar a ser a conservação dos patrimônios.

Segundo Ortiz, havia então um descompasso entre as falas dos Conselheiros do CFC e do Ministro da Educação. Havia uma tensão entre tradição e modernidade, entre cultura (qualidade) e técnica (quantidade), entre cultura popular (qualidade) e cultura de massa (quantidade). Para os membros do CFC, a sociedade moderna é identificada com o economicismo, 
com o tecnicismo, lida como cópia de modelos estrangeiros, o que leva à "asfixia do humanismo". Assim, os membros do CFC fazem a crítica da modernização em nome do humanismo.

Se isto é assim, cabe perguntar: Como conciliar a ação modernizadora do Estado com esse discurso tradicional? A ideologia tradicional dos membros do CFC não se adequaria ao desenvolvimento do capitalismo que tem o Estado como promotor da racionalidade e da técnica. Haveria então necessidade de contar com um novo intelectual, cujos exemplos estão, inicialmente, no Instituto Nacional de Cinema (INC), criado em 1966 e absorvido mais tarde pela Embrafilme (1969).

Sintetizando os argumentos de Ortiz, podemos dizer que para ele os intelectuais tradicionais do CFG seriam incapazes de elaborar um plano nacional de cultura para os novos tempos e, em seu lugar, aparecem novos gestores da área de cultura. Assim, o Estado se volta para os intelectuais disponíveis, aqueles que, em suas áreas, se afinam com as propostas modernizantes do governo militar.

Após os textos inaugurais de Miceli e Ortiz, já mencionados, foram publicados outros importantes trabalhos sobre o Instituto do Patrimônio Histórico e Artístico Nacional (Iphan) (GONÇALVES, 1996; FONSECA 1997) e sobre a Fundação Nacional de Artes (Funarte) (BOTELHO, 2000). O CFC volta a ser objeto de pesquisa no doutorado de Tatyana de Amaral Maia, publicada no livro Os cardeais da cultura nacional: O Conselho Federal de Cultura e o papel cívico das políticas culturais na ditadura civil-militar (1967-1975) (MAIA, 2012).

A autora vai analisar a composição do CFC, formado por 24 membros fundadores, e que teve entre seus conselheiros Josué Montelo, principal articulador do Conselho, Pedro Calmon, Gilberto Freyre, Djacir Menezes, Guimarães Rosa, Rachel de Queiroz, Ariano Suassuna, Roberto Burle Marx, Afonso Arinos de Melo Franco, Hélio Vianna, todos com longa experiência como intérpretes da nação e de continuada inserção nos órgãos do Estado brasileiro. Daí terem sido nomeados por Gilberto Freire como "cardeais" da cultura nacional. Tais nomes compõem uma geração longeva, que esteve entrelaçada com movimentos culturais, literários e políticos desde a década de 1920 até os anos 1970.

A rede de sociabilidade dos conselheiros é examinada a partir do levantamento biográfico e das trajetórias dos seus membros tomando como marcadores cargos no espaço do MEC, participação em movimentos culturais e políticos, em academias de letras e institutos históricos e geográficos, em 
periódicos, em mandatos no legislativo. Tais dados oferecem uma visão clara da constituição de uma elite cultural, ainda que isso não signifique a existência de um grupo homogêneo ou que não haja áreas de conflito entre eles.

Para muitos membros do Conselho, a cultura nacional se encontrava ameaçada, principalmente, pela invasão de valores estrangeiros que se consolidavam pela indústria cultural. O CFG reafirmava concepções de cultura em que língua, território e passado comum eram fundamentos centrais e se posicionava contra o desenvolvimento da cultura de massas.

Tatyana Maia (2012) examina os fundamentos das políticas defendidas pelo Conselho mostrando como seus principais eixos estiveram centrados na cultura regional, na identidade e na memória nacionais, o que confirma em linhas gerais o que já tinha sido indicado por Renato Ortiz.

Diante das ameaças e das mudanças arriscadas que ameaçavam a cultura nacional, volta-se a valorizar o civismo, considerado como valor social superior capaz de proporcionar a autodefesa da nação. Hinos, heróis, datas e mitos de origem vão compor o aparato simbólico que passa a ser defendido pela Comissão Nacional de Moral e Civismo do MEC e que constituirão o cerne das disciplinas "Educação Moral e Cívica" e "Estudos dos Problemas Brasileiros" dos currículos oficiais. O trabalho patriótico de devoção à pátria, de defesa do Estado nacional teria por objetivo também afastar os jovens das ideologias perniciosas que invadiam as escolas secundárias e universidades.

O CFC entra nessa mesma trilha de valorizar as comemorações de datas históricas - vale lembrar o Sesquicentenário da Independência em 1972 -, com a publicação de livros e de obras coletivas, muitas delas de autoria dos próprios conselheiros, e de calendários culturais de efemérides que acabam marcando a atuação do Conselho como predominante no campo simbólico do civismo. Pode-se dizer que a ideologia tradicionalista dos "velhinhos" do CFC assim como sua prática não se mostravam adequadas ao desenvolvimento do capitalismo que tem no Estado seu motor.

Os objetivos do CFC envolviam, além da distribuição de recursos para projetos da área, uma função executiva como centralizadora na organização das ações culturais. Tal atribuição configuraria o que pode ser entendido como política cultural, ou seja, como ação estatal organizada, contínua, com recursos destinados exclusivamente ao setor. Maia (2012) analisa igualmente os impasses, as disputas internas, as verbas deficitárias, assim como as propostas de estruturação da área cultural que acabam prevalecendo. O esgotamento do CFC pode ser apontado quando Ney Braga assume o MEC em 1974. 
Vale mencionar que entre os estímulos patrocinados pelo CFC estáa criação de conselhos estaduais e municipais de cultura, considerados embrião de um sistema nacional de cultura, sistema que só nos anos 2010 vai ser montado. Esse eixo da cultura regional se apresenta como um interessante marco da atuação do CFC e se fez presente pelo projeto de implantação de Conselhos Estaduais de Cultura, merecendo destaque a fundação da Secretaria de Cultura do Estado do Ceará, primeira do país, e de seu respectivo Conselho Estadual (COSTA, 2011).

Mas será outro setor do MEC - o Departamento de Ação Cultural (DAC) - que passará a contar, a partir de 1973, com recursos do Fundo Nacional de Desenvolvimento da Educação e que representará, por assim dizer, o lado modernizador. No seu espaço surgirá o importante Programa de Ação Cultural (PAC), cuja criatura mais conhecida e reconhecida é a Funarte. Entre os projetos desenvolvidos pela Funarte vale citar o Projeto Pixinguinha, o projeto de seminários organizados por Adauto Novaes e o Projeto Bandas, que tornou o Brasil exportador de instrumentos de sopro. Esse outro órgão do MEC, o DAC, que acabamos de mencionar, vai elaborar a Política Nacional de Cultura e trazer para dentro da burocracia do MEC outra perspectiva de lidar com a cultura e de gerenciar as políticas culturais.

Essa literatura fornece bases, pistas, temas para novas pesquisas e para a produção de novas fontes, como a realização de entrevistas com os principais responsáveis por diversos órgãos do governo no campo da cultura. Vale lembrar que o levantamento do arquivo Geisel depositado no CPDOC (BOMENY, 2002) também pode ser considerado uma fonte fundamental para novas pesquisas. Sabemos que estudar a ação do Estado envolve, por um lado, tomar os documentos de arquivos e os artigos das revistas oficiais. Por outro lado, o depoimento dos técnicos envolvidos diretamente em diferentes projetos oferece uma interpretação muito mais viva e matizada da realidade.

Com isto em mente demos andamento à realização de entrevistas com técnicos que participaram do processo de construção de órgãos e de políticas públicas na área da cultura no período em que a cultura ainda fazia parte do Ministério da Educação, ou seja, até 1985. Iniciamos as entrevistas colhendo os depoimentos de Amália Lucy Geisel (do CFC), de Roberto Parreira (Funarte), de Henrique Oswaldo de Andrade no Programa Integrado de Reconstrução de Cidades Históricas do Nordeste (PCH), de Roberto Moreira (do gabinete de Aloísio Magalhães) e de Isaura Botelho (Funarte). Pudemos contar também com o depoimento de José Silva Quintas (do Centro Nacional 
de Referência Cultural, CNRC), já publicado pelo Iphan, em 1994. É possível adiantar que alguns depoimentos confirmam as hipóteses já aventadas, apresentando ângulos novos ou complementares; outros questionam as versões existentes e abrem trilhas para novas interpretações.

Muitos outros atores ainda precisam falar para que seja possível montar um quadro mais abrangente e multifacetado sobre as atuações, os impasses e as políticas que acabaram sendo implementadas. A lista de outros entrevistados é grande e cresce à medida que, ao se fazer entrevistas, os depoentes indicam a relevância de outros nomes.

\section{O Programa de Cidades Históricas}

Uma premissa presente na literatura diz que os intelectuais tradicionais estavam envolvidos com o patrimônio (o que é questionável, já que Aloísio Magalhães, que não é considerado um tradicionalista, acabou atuando e privilegiando também a área de patrimônio), enquanto os intelectuais modernos eram executivos que inseriam a cultura no mundo do consumo capitalista. Vamos dirigir nossa atenção a um programa voltado para o patrimônio e que incorporou estratégias modernas em sua organização e funcionamento: o Programa de Cidades Históricas (PCH), criado dentro da Secretaria de Planejamento da Presidência da República (SEPLAN).

Em 1973 foi criado o Programa Integrado de Reconstrução de Cidades Históricas do Nordeste (PCH), por portaria do Ministro do Planejamento, João Paulo dos Reis Velloso. Ligado à Secretaria do Planejamento (SEPLAN), o programa dispunha de recursos do Fundo de Desenvolvimento de Programas Integrados.

Foram selecionadas 28 cidades nos nove estados nordestinos cujos monumentos, casas e igrejas representassem os ciclos da cana-de-açúcar, do couro e do algodão. O grupo interministerial que projetou o programa (Ministério do Planejamento, direção; da Indústria e Comércio, representado pela Empresa Brasileira de Turismo, Embratur; do Interior, representado pela Superintendência de Desenvolvimento do Nordeste, Sudene e da Educação e Cultura, representado pelo Iphan) pensou na preservação dos monumentos tombados atrelando-a à viabilidade de sua utilização econômica e à geração de renda no Nordeste. Os monumentos que recebessem recursos para sua restauração deveriam se tornar economicamente rentáveis, pela atuação do turismo. Era um programa interministerial com a finalidade de revitalizar 
os núcleos históricos em estreita colaboração com a comunidade, formando mão de obra especializada e gerando empregos.

O PCH aprova projetos que passam a ser executados com recursos do Fundo, faz convênios com fundações culturais e empresas estaduais de turismo. Ao Iphan cabia aprovar a restauração e acompanhar os trabalhos. O Programa dispunha de recursos e de autonomia gerencial, o que viabilizou importantes iniciativas no campo da preservação do patrimônio na região Nordeste. A recuperação do Largo do Pelourinho (Salvador), diversas restaurações em Olinda (PE), a restauração do Forte dos Reis Magos (Natal), o início dos trabalhos nos sobrados de São Luís (MA), a restauração do Teatro José de Alencar (Fortaleza) e do Teatro 4 de Setembro (Teresina) são projetos creditados ao $\mathrm{PCH}$. Deve-se também atribuir ao Programa a transformação de antigos presídios em Recife, Natal e Fortaleza em Casas de Cultura, fortalecendo o artesanato e o turismo. A entrevista com Henrique Oswaldo de Andrade ${ }^{1}$, que assumiu a direção do programa, está sendo a principal fonte para essas reflexões, que sinalizam aspectos de modernidade da gestão no campo tradicional do patrimônio.

Henrique Oswaldo de Andrade é originário de família mineira de elite e membro de uma geração da qual fazem parte Paulo Haddad e Élcio Costa Couto. Foi para Brasília a convite de João Paulo dos Reis Velloso, ministro do Planejamento, mais especificamente, de Élcio Costa Couto, secretário geral do Ministério do Planejamento. Foi convocado para realizar uma avaliação do PCH, que tratava do patrimônio associando-o ao turismo, fórmula engenhosa que permitia incluir a cultura em órgão de planejamento do governo federal.

Para Henrique Oswaldo, Velloso fora sensibilizado pela situação de penúria do patrimônio do Nordeste, o que o leva a criar em 1973 o $\mathrm{PCH}$. O programa, cujos recursos vinham de um Fundo ligado ao MEC, reservava 20\% para o IPHAN, desde que algumas exigências fossem observadas. Henrique Oswaldo vai então para o Ministério do Planejamento fazer a avaliação do PCH e identifica como seus principais problemas: falta de pessoal qualificado para cuidar da restauração do patrimônio, ausência de projetos e dificuldade

\footnotetext{
${ }^{1}$ Realizada em 07 de abril de 2005 por Lia Calabre e Lucia Lippi no âmbito do Projeto Pronex do do Centro de Pesquisa e Documentação de História Contemporânea do Brasil (CPDOC) da Fundação Getúlio Vargas (FGV).
} 
de manutenção do que era restaurado. A partir desse diagnóstico, o PCH passou a requerer que o planejamento de novas ações incluísse também o uso futuro do bem a ser restaurado assim como a existência de uma instituição especializada no local. Essas passaram a ser as exigências para que os recursos do programa chegassem a um projeto.

Segundo o entrevistado, as contribuições do PCH foram criar um modelo de gestão para a área, propugnar pela junção de esforços entre municípios, estados e governo federal e incentivar a criação de instituições locais. Foi a partir desse programa que muitos municípios e estados criaram instituições e elaboraram uma legislação relativa aos bens patrimoniais, como, por exemplo, o caso de Olinda. Com o PCH, a preservação de bens culturais passou pela primeira vez a integrar os planos de desenvolvimento econômico. Foi feito um modelo para avaliar custos e benefícios e assim justificar os recursos alocados ao programa. Dispondo de indicadores econômicos pôde o Programa ser acompanhado pelo sistema de controle do governo e foi possível proceder a uma comparação com outros programas ligados ao restauro de bens patrimoniais, como o Monumento do Banco Interamericano de Desenvolvimento, BID.

A burocracia do PCH, segundo Henrique Oswaldo, envolvia apenas cerca de quatro pessoas, entre elas Silva Teles do Iphan, sob sua coordenação. Os técnicos do Iphan, no início, sentiram-se ameaçados com a existência do PCH, mas com a chegada de Irapoan Cavalcanti de Lyra ao Iphan essa ameaça, como mencionaremos adiante, foi contornada.

A reforma organizacional de que o IPHAN necessitava começou a ser feita, e os recursos do Programa direcionados ao órgão (20\%) começaram a ser repassados. Esse dinheiro era muito mais do que o IPHAN dispunha em seu orçamento, e imediatamente muitos escritórios regionais começaram a se interessar pelo programa. Alguns municípios que já tinham instituições locais começaram a receber recursos, como Olinda e Salvador.

As primeiras atividades da gestão de Henrique Oswaldo no PCH envolveram "manualizar", ou seja, produzir manual de obra, de operação para montagem de programas estaduais em que estava embutida a ideia de roteiro de turismo. O PCH também abriu espaço para o planejamento urbano de núcleos históricos e até para arqueologia. Ou seja, o programa era muito flexível, podia incluir qualquer projeto, qualquer ideia que fosse considerada inovadora no sentido de facilitar a preservação.

Henrique Oswaldo vai destacar como uma das atividades mais relevantes a formação de pessoal. Diante das dificuldades de fazer parte da grade 
regular da universidade, o Programa se ligou à extensão universitária da Universidade Federal de Pernambuco (UFPE), com um curso de quatro meses. Os alunos (engenheiros ou arquitetos) deveriam estar ligados a instituições locais, tinham que apresentar e desenvolver projetos durante o curso e o compromisso de implementá-los ao retornar. E mais, os projetos recebiam financiamento se estivessem nos roteiros aprovados pelo programa. Outros cursos se seguiram em Minas e na Bahia. Cada curso gerava de 30 a 40 projetos e, até o final dos anos 1970, foram formados 126 técnicos que, por sua vez, formaram equipes locais e/ou estaduais. Na avaliação de Henrique Oswaldo, a importância de tais equipes pode ser confirmada, já que foram elas que garantiram a sobrevivência das atividades do patrimônio durante o período devastador do governo Collor.

Outro ângulo do depoimento de Henrique Oswaldo é a valorização do contato com a área internacional representada principalmente pela Unesco. A conexão entre as instâncias de preservação do patrimônio no Brasil e a presença da Unesco mencionada no depoimento começam a ser explicitadas em trabalhos como o de Claudia Feierabend Baeta Leal (2012), que toma como parâmetro as visitas do inspetor Michel Parent ao Brasil em 1966 e 1967. O relatório "Proteção e valorização do patrimônio cultural brasileiro no âmbito do desenvolvimento turístico e econômico”, de autoria de Michel Parent, foi, segundo a autora, relevante tanto no âmbito dos envolvidos com a preservação do patrimônio no Brasil, à época chamada de Diretoria do Patrimônio Histórico e Artístico Nacional (DPHAN), quanto para os demais consultores da Unesco nas visitas seguintes ao Brasil.

O contato do DPHAN com a Unesco se fazia relevante através de acordos de cooperação técnica assinados a partir de 1964, que previam missões, visitas de peritos a cidades históricas brasileiras, cooperação técnica e, principalmente, ajuda para reformular e reforçar a atuação frente a demandas por novas políticas para a conservação do patrimônio. Entre as novas políticas está a assistência técnica da Unesco para o estudo e execução de um programa com vistas à aceleração do movimento turístico para a proteção e a valorização do patrimônio cultural e dos sítios naturais. Assim a Unesco defende o programa de turismo cultural que envolve, entre outros tópicos, a reconversão dos usos dos edifícios restaurados. O turismo aparece como fonte do desenvolvimento da renda nacional e vai favorecer a salvaguarda do patrimônio cultural que se encontrava em perigo de desaparecer.

A ênfase no turismo trazida pela Unesco e presente em suas Cartas Patrimoniais encontrava eco no Brasil, já que aqui tinha sido criada a 
Empresa Brasileira de Turismo (Embratur), em 1966. Mas o turismo ganha importância, reconhecimento e, acima de tudo, respeitabilidade graças às recomendações e orientações da Unesco. O contato entre a DPHAN e a Embratur vai se efetivar em 1975, quando os dois órgãos vão ter uma ação conjunta exatamente no Programa Integrado das Cidades Históricas.

Se formalmente existia uma ação conjunta, as coisas não caminharam pacificamente. Henrique Oswaldo, ao comentar as mudanças da estrutura organizacional do campo da cultura, observa que a Embratur, que fazia parte do núcleo original do $\mathrm{PCH}$, teve pouca participação na dinâmica do Programa.

As mudanças decorrentes da incorporação do PCH e do Centro Nacional de Referência Cultural (CNRC) ao Iphan e, mais tarde, as mudanças no próprio Iphan deram a possibilidade de colocar em funcionamento um novo modelo de gestão para cada projeto, configurado como "gestão matricial", que será implementado, como veremos adiante, na Fundação Pró-Memória.

A migração do PCH para o IPHAN significou a ida também do fundo do orçamento da Seplan para o Iphan e depois para a Pró-Memória. Segundo Henrique Oswaldo, o ministro João Paulo dos Reis Velloso trabalhava com programas, tendo cada um seu fundo, o que veio garantir à Fundação PróMemória uma situação especial para seus técnicos (curva salarial corrigida em período de inflação). Isso continuou a funcionar desse modo, mesmo após a morte de Aloísio Magalhães, e vigorou até 1985, com a criação do Ministério da Cultura (MinC).

$\mathrm{Na}$ entrevista aqui mencionada, escolhemos tratar apenas os trechos que apontam a inovação organizacional na área de atuação cultural do governo. O depoimento de Henrique Oswaldo assim como outros trabalhos recémpublicados mencionam que as transformações e inovações organizacionais foram decorrentes da gestão do João Paulo dos Reis Velloso na Seplan e no Ministério do Planejamento. Atreladas ao ministro foram criadas "ilhas de excelência" da administração pública federal. Essas "ilhas" foram ameaçadas com a Constituição de 1988, que criou o Regime Jurídico Único com perda de flexibilidade e de eficiência, nos diz João Paulo dos Reis Velloso, referindose ao Instituto de Pesquisa Econômica Aplicada (Ipea) e à Financiadora de Estudos e Projetos (Finep). Entre as "ilhas" indicadas pelo ministro podemos acrescentar a Funarte, o PCH e a Fundação Pró-Memória, órgãos que ofereceram uma gestão eficiente e moderna.

Sabemos que as Fundações foram também pensadas como uma solução para vencer as barreiras e tentar inovações na administração pública. 
Segundo Amália Lucy Geisel (entrevista em 3.03.2005), a época, em torno de 1976, "foi o boom das fundações. O que eram as fundações? As fundações eram a salvação das instituições públicas, davam certa liberdade em alguns aspectos, afrouxavam, possibilitavam ações mais rápidas e eram sim a grande solução”.

O período entre 1979 a 1981 pode ser considerado assim um tempo de inovações organizacionais na área de cultura do MEC pela criação da Secretaria de Assuntos Culturais (Seac), pelas mudanças no Sphan (que como Iphan já tinha incorporado o CNRG e o PCH), que detinha o poder normativo, e pela criação da Fundação Nacional Pró-Memória.

\section{A nova Sphan e a Fundação Nacional Pró-Memória}

Em 1979 é criada a Secretaria de Assuntos Culturais (SEAC) no início da gestão de Eduardo Portela, no Ministério da Educação, para congregar todas as instituições de cultura do Ministério. A Secretaria trouxe uma nova formulação para a política cultural do ministério, preconizando ações culturais voltadas para a população de baixa renda e para as "regiões carentes". A cultura passa a ser entendida como o principal motor de resoluções dos problemas sociais do país. O maior mérito da SEAC foi instaurar e aprofundar o debate sobre política cultural. O novo órgão foi conduzido por Márcio Tavares d'Amaral e, a partir de dezembro de 1980, por Aloísio Magalhães.

Foram tantas as mudanças organizacionais que considero importante mencioná-las novamente. Em 13 de novembro de 1979 é criada a Secretaria do Patrimônio Histórico Artístico Nacional (SPHAN), pela fusão do CNRC e do PCH ao IPHAN. A nova secretaria ficou com a responsabilidade normativa e legal, o poder de intervenção do Estado. O projeto era parte de um modelo institucional moderno e econômico, vindo a funcionar junto de outro órgão, a Fundação Nacional Pró-Memória (FNPM). Aloísio Magalhães assumiu sua chefia, acumulando a função com a condução da SEAC.

Concomitantemente à SPHAN é criada, em 26 de novembro de 1979, a Fundação Nacional Pró-Memória (FNPM), com a função operacional de preservação em nível nacional. Em outubro de 1980, a FNPM absorve a Biblioteca Nacional, o Instituto Nacional do Livro, o Museu Imperial, o Museu Histórico Nacional, o Museu da República e o Museu Villa-Lobos, todos órgãos do Ministério da Educação e Cultura. 
O Boletim SPHAN / Pró-Memória foi um importante recurso de divulgação das atividades desempenhadas pelos órgãos responsáveis pelas questões culturais no Ministério da Educação: a Secretaria do Patrimônio Histórico e Artístico Nacional e a Fundação Nacional Pró-Memória. Apesar das funções e atuações distintas - o primeiro de caráter mais normativo e o segundo mais executivo - no Boletim estão apresentadas as atuações conjuntas. Foram 47 volumes publicados entre julho/agosto de 1979 - quando os dois órgãos, SPHAN e Pró-Memória estavam sendo constituídos - a março/abril de 1989. Durante esse período, o Boletim acompanharia a constituição da Secretária Nacional de Cultura e do posterior Ministério da Cultura.

A Secretaria Nacional da Cultura (SEC), criada em 10 de abril de 1981, através da portaria ministerial n. 274, foi resultado da fusão da SEAC com a SPHAN, ambas comandadas por Aloísio Magalhães. Assim, a Secretaria da Cultura passou a ter duas subsecretarias (com o nome das antigas secretarias originais): a Subsecretaria do Patrimônio Histórico e Artístico Nacional (SPHAN) e a Subsecretaria de Assuntos Culturais (SEAC), cada uma delas com suas respectivas fundações, a Pró-Memória e a Funarte. As demais instituições - Embrafilme, Fundação Casa de Rui Barbosa e a Fundação Joaquim Nabuco - ficaram subordinadas diretamente ao Secretário da Cultura, Aloísio Magalhães.

A figura central em todo esse processo de transformação dos órgãos do Estado responsáveis por políticas culturais é Aloísio Magalhães (1928-1982). Artista plástico, design reconhecido pela criação do logotipo do $4^{\circ}$ Centenário do Rio de Janeiro em 1964, do símbolo para a Bienal de São Paulo em 1965. Participou da fundação da Escola Superior de Desenho Industrial (ESDI) no Rio de Janeiro. Trabalhou para o Banco Central, desenhando novo papelmoeda, o cruzeiro novo, e foi também consultor da programação visual da reforma dos Correios e Telégrafos. Será com essa bagagem que vai formar o grupo em Brasília que dará origem ao CNRC e assumir a direção da nova estrutura que gerenciará as políticas de patrimônio: a nova SPHAN e a FNPM.

A Subsecretaria do Patrimônio Histórico e Artístico Nacional (SPHAN) junto com a Fundação Nacional Pró-Memória (FNPM) tinham como objetivo institucionalizar a mudança de forma permanente, evitando a rigidez burocrática. Para tornar isso possível, foi necessário proceder a inovações na gestão administrativa. Esses dois órgãos vão se tornar núcleo do que seria mais tarde o Ministério da Cultura. Dali sai o documento Diretrizes para Operacionalização da Política Cultural do MEC, base de referência para os 
artigos 215 e 216 da Constituição de 1988.

Aloísio Magalhães morre em 1982, quando participava de uma reunião da Unesco em Veneza. Suas conferências, entrevistas e discursos foram reunidos no livro E triunfo? - a questão dos bens culturais no Brasil (1985) onde estão suas principais ideias sobre o papel fundamental da cultura no desenvolvimento econômico e social.

Para Aloísio Magalhães, o Brasil, país onde coexistem megalópoles e comunidades isoladas, ainda não teria logrado construir uma imagem própria, a partir de sua produção material e simbólica. Isolado em um continente em decorrência da língua e da distância, o Brasil viveu às voltas com problemas de sobrevivência, e sua cultura não conseguiu se sedimentar. O país absorve de modo avassalador valores estranhos que atingem os meios de comunicação de massa e o pensamento intelectual. Daí ser necessária, a seu juízo, a conscientização de nossa cultura para enfrentar o avassalador processo de transplante. Os bens culturais passam a ser vistos como uma espécie de "vacina".

Até então, segundo Aloísio Magalhães, tinham sido valorizados os bens móveis e imóveis impregnados de valor histórico, mas que representavam bens de criação individual. Daí terem ficado de fora o fazer popular, inserido no cotidiano, e que expressavam os bens culturais vivos. Sua proposta é voltar ao projeto original de Mário de Andrade de "tradições móveis". Aloísio evita noções de "cultura popular" e de "folclore", já que não vê bens culturais como sobrevivências do passado. Nos anos 1980 ele cunhou a expressão "patrimônio cultural não-consagrado", que se refere a manifestações não reconhecidas até então como bens culturais.

Sob a gestão de Aloísio Magalhães foram encaminhadas as primeiras inscrições brasileiras na Lista do Patrimônio Mundial da Unesco: Ouro Preto (1980) e as ruínas de São Miguel das Missões (1981). Também sob sua gestão foi realizado o primeiro Seminário nas Cidades Históricas, com apoio da Fundação Roberto Marinho, dando espaço para o debate em torno do uso turístico e da autossustentabilidade dos bens tombados, cujo caso exemplar foi a restauração da cidade de Tiradentes (MG).

Após a morte de Aloísio, Marcos Vinícius Vilaça ocupou a direção da Secretaria de Cultura, e em sua gestão foi publicado um livro com as transcrições dos Seminários e Encontros de Cultura acontecidos entre 1982 e 1984, chamado Por uma Política Nacional de Cultura. (Brasília, Fundação Nacional Pró-Memória, 1984). 
A Fundação Nacional Pró-Memória também mereceria uma atenção específica. Fica aqui apenas a observação sobre a criação de uma fundação com o nome "pró-memória", ou seja, a favor da lembrança. Isto corresponde perfeitamente a uma visão da época sobre a cultura nacional e os perigos que ela enfrentava. Os anos 1970 e 1980 viviam uma tensão entre a modernidade tecnológica em curso e uma representação sobre a cultura brasileira que guardava resquícios do movimento de defesa do folclore. De qualquer modo, passa-se a defender o registro e o salvamento das manifestações culturais populares, fossem elas folclóricas ou não, que estariam sendo ameaçadas.

Na criação do Pró-Memória, acionou-se um argumento similar ao usado na criação do Sphan, a "retórica da perda", como nos diz o antropólogo José Reginaldo Gonçalves dos Santos. Ressaltava-se o perigo, o esmagamento das culturas locais e regionais pela cultura urbana, pela cultura de massa típica da modernidade capitalista. Frente a esse perigo, está o povo, concebido desde os românticos como uma totalidade homogênea e autônoma, com criatividade espontânea e autêntica. O povo é entendido como o que guarda o arcaico, aquilo que conseguiu sobreviver, derivado de uma vivência comunitária que se via ameaçada. Diante do processo em curso, imposto, inevitável, o que cabia fazer era salvar pelo registro, pela gravação, pelo documento. A salvação garantia a identidade nacional/regional/local. Salvar era registrar a memória do Brasil para que ela pudesse ser ouvida/apreciada pelas gerações futuras, mesmo que as práticas sociais que deram origem aos bens culturais não mais existissem. O trabalho de salvação, de preservar a memória da cultura popular agrega uma distinção aos apreciadores, já que denota certo gosto sofisticado, diferente do gosto médio, e ao mesmo tempo indica certa comunhão entre os apreciadores e o povo.

Sob a ótica da modernização da administração pública, vale registrar a contribuição de Irapoan Cavalcanti de Lyra no campo da cultura. Técnico em administração pública, ele atuou em diversos órgãos do governo, entre eles a Fundação Casa de Rui Barbosa, os Correios e Telégrafos e a Fundação Pró-Memória. Sobre sua atuação na área de patrimônio, Irapoan nos conta em entrevista concedida ao CPDOC em 2002: "Fui para a Secretaria do Patrimônio Histórico e Artístico Nacional, a Sphan, a convite de Aloísio Magalhães, que conheci durante a reforma dos Correios, (...); ficamos amicíssimos até sua morte. Aloísio assumiu a Sphan em 1979, na gestão do ministro Eduardo Portela". E continua: "Naquele momento, o quadro da Sphan estava reduzido a meia dúzia de abnegados, que, como loucos, 
andavam pelo Brasil inteiro". Prossegue em seu relato: "Daqui a pouco nem eles, porque vão morrer ou se aposentar, e não teremos como contratar gente jovem. Dentro da administração direta é impossível; teremos que criar uma fundação”. E foi assim que nasceu a Fundação Pró-Memória.

O Instituto do Patrimônio, criado em 1937 por Rodrigo de Melo Franco, contou com arquitetos, engenheiros, historiadores e museólogos excepcionais. Porém, na avaliação de Irapoan, sofreu a deterioração que atingiu toda a administração pública brasileira; seus técnicos mais jovens começaram a ir embora, porque precisavam ganhar a vida, já que os salários eram irrisórios. A Pró-Memória ofereceu algumas vantagens para o pessoal que optasse... O salário era muito melhor, com perspectivas de crescimento na carreira, ainda que envolvesse a troca da estabilidade pela rentabilidade.

A Fundação foi criada e a Sphan foi mantida já que, explica Irapoan:

“A Sphan tinha dois poderes fundamentais, que são exclusivos da administração direta: poder de polícia, isto é, podia embargar uma obra que estivesse destruindo o patrimônio e aplicar uma multa, chegando até mesmo à ordem de prisão, por exemplo; e o poder de Estado, de criar normas que a sociedade tem que cumprir, como a possibilidade de tombar um bem e criar regras para sua utilização. Assim, mantivemos o Patrimônio apenas com o secretário nacional e os secretários estaduais".

"A Pró-Memória, por sua vez, não tinha estrutura, coisa que chocava as pessoas. Não tinha departamentos, divisões, nada. Tínhamos um banco de recursos humanos, com arquitetos, engenheiros, historiadores etc., e pessoas de fora do sistema que eram eventualmente contratadas. (...) Fazíamos uma administração por projeto. Na época, era uma novidade chocante. Que eu saiba, a PróMemória é a única organização pública brasileira que viveu, com grande êxito, sem estrutura interna. Como o processo de produção não era conhecido, ele se organizava na hora da produção e se dissolvia quando aquela produção deixava de existir”.

O fim da Fundação Pró-Memória, segundo Irapoan, se deveu a um

"erro administrativo lamentável do ministro Celso Furtado, ministro da Cultura do governo Sarney (...). Tínhamos concebido um sistema só, que exercia o poder de Estado e de polícia com a Sphan [Secretaria do Patrimônio Histórico e Artístico Nacional] e a atividade de preservação com a Pró-Memória. O secretário 
de Cultura era o presidente da Pró-Memória e recebia um único salário. Celso Furtado escolhe duas pessoas: para secretário da Sphan, Ângelo Osvaldo, pessoa de grande conhecimento - hoje é secretário de Cultura de Minas Gerais -, uma pessoa notável; para presidente da Fundação Pró-Memória, Joaquim Falcão”.

Irapoan contra-argumenta com o ministro:

"Acho que o senhor vai cometer um engano fatal ao nomear uma pessoa para a Pró-Memória e outra pessoa como secretário do Patrimônio. Por melhores que sejam, vão entrar em atrito, porque dois comandantes não comandam um só navio, e o sistema foi concebido para ser uma coisa só. Mexa, então, no sistema, desmembre-o, caso contrário o conflito será inevitável.”

\section{A proliferação de novos formatos organizacionais}

Na curta gestão de Eduardo Portela no MEC é criada, como já mencionamos, a Secretaria de Assuntos Culturais (SEAC) assim como dois programas: o Pronasec (Programa nacional de ações socioculturais para o meio rural) e o Prodasec (Programa nacional de ações socioculturais para as periferias urbanas). É também quando, em 1979, o PCH passa a ser incorporado ao IPHAN.

Na gestão do ministro Rubem Ludwig, em 1981, foi criada a Secretaria de Cultura (SEC) tendo duas subsecretarias: a Subsecretaria de Assuntos Culturais, SEAC com a sua fundação, a Funarte; e a Subsecretaria do Patrimônio Histórico e Artístico Nacional, SPHAN com sua fundação, a Fundação Pró-Memória. Aloísio Magalhães, que vem da direção do CNRC, vai para o IPHAN/ Sphan, e, por fim, chega à direção da SEC. É dessa posição que ele pode dizer que "mais vale uma secretaria forte do que um ministério fraco".

Essa organização, com a vigência de uma Secretaria de Cultura, é preciso lembrar, foi recriada no governo Collor, tendo como secretário Ipojuca Pontes e depois Sérgio Paulo Rouanet. Essa secretaria também se dividiu em dois grandes grupos, tendo de um lado bens culturais e de outro os bens patrimoniais: o Instituto Brasileiro de Arte e Cultura (IBAC), dirigido por Mário Machado, e o Instituto Brasileiro de Patrimônio Cultural (IBPC), dirigido por Lélia Coelho Frota. Mas essa reformulação atabalhoada, com a 
extinção da Funarte, da Pró-Memória, da Fundacen, da Embrafilme, entre outros órgãos e fundações, levou a um caos tão paralisante e a uma revolta tão grande que nada pode ser dito - um tipo de "silêncio obsequioso" parece calar os que ainda estão vivos e declarar de antemão que nada ali vale alguma coisa ou pode ser aproveitado para futuras gerações.

Figuras importantes da época não falam sobre esse tempo traumático no campo das instituições culturais. Paulo Sérgio Rouanet se recusa a dar entrevistas sobre o tema, o mesmo acontece com Mário Machado, que dirigiu o IBAC. Desconheço se Lélia Coelho Frota registrou antes de morrer sua experiência a respeito! Talvez seja necessário passar mais 50 anos para que se possa ter mais e melhores informações sobre essa experiência traumática durante o primeiro governo eleito pelo voto direto após os anos de ditadura e de transição para a democracia.

Rodrigo Patto Sá Motta, em seu livro (2014), procura analisar as relações entre a elite universitária e o Estado autoritário, classificando-as em adesão, resistência e acomodação. Vai mostrando as contradições e ambiguidades que atingem as estratégias de mão-dupla que fazem parte da longa tradição da cultura política brasileira. Faz também algumas indicações comparativas entre as duas ditaduras: o regime militar e o Estado Novo de Vargas.

Sobre a comparação entre as duas ditaduras, gostaria de levantar algumas hipóteses que se referem à memória desses dois períodos e que ainda precisam ser mais bem investigadas. Embora o Estado Novo tenha recebido rejeição nos anos da democracia liberal de 1945, muitas das instituições criadas no campo da cultura, o Instituto do Patrimônio Histórico e Artístico Nacional, o Instituto Nacional do Teatro, o Instituto Nacional do Livro, entre muitas outras, continuaram a atuar e a ser respeitadas. Isto não aconteceu com as instituições de cultura no processo de democratização após a ditadura militar... A herança do que foi construído no campo da cultura durante a ditadura militar teve rejeição maior e foi amaldiçoada por sua recuperação no governo Collor.

O regime militar promoveu diferentes projetos culturais, alguns que iam para além do patriotismo tradicional ainda que nem todos tivessem fundamentos ideológicos bem elaborados e conseguissem ser hegemônicos. Só para lembrar: parece-me que a atuação da Fundação Pró-Memória e a de Aloísio Magalhães não se enquadram exatamente na reafirmação do patriotismo tradicional. O mesmo pode ser dito do Projeto Pixinguinha abrigado pela Funarte! Já levantei, meio brincando, meio falando sério, que 
os ideólogos do Estado Novo eram melhores do que os ideólogos da ditadura militar...

\section{Referências}

BOMENY, Helena.

(2002). Educação e cultura no Arquivo Geisel. In: Maria Celina D'Araújo; Celso Castro (Orgs.); Dossiê Geisel. Rio de Janeiro, FGV. p. 89-103.

BOTELHO, Isaura.

(2000). Romance de formação: FUNARTE e política cultural 1976-1990. Rio de Janeiro, Casa de Rui Barbosa.

CALABRE, Lia.

(2005). Política cultural no Brasil: um breve histórico. In: Políticas culturais: diálogo indispensável. Rio de Janeiro: Casa de Rui Barbosa, 2005.

COHN, Gabriel.

((1984). A concepção oficial da política cultura nos anos 70. In: Sério Miceli (Org.); Estado e Cultura no Brasil. São Paulo: Difel. p. 87-96.

COSTA, Lílian Araripe Lustosa da.

(2011). A política cultural do Conselho Federal de Cultura 1966-1976. Dissertação de mestrado apresentada ao Programa de Pós-Graduação em História, Política e Bens Culturais do Centro de Pesquisa e Documentação de História Contemporânea do Brasil (CPDOC) da Fundação Getúlio Vargas (FGV).

D'ARAUJ0, Maria Celina e CASTRO, Celso (Orgs.).

(2004). Tempos modernos: João Paulo dos Reis Velloso; memórias. Rio de Janeiro, FGV.

(2002). Entrevista de Irapoan Cavalcanti de Lyra. In: Helena Bomeny; Marly Silva da Motta (Orgs.); A escola que faz escola: Ebape, 50 anos. Rio de Janeiro, Editora FGV. p. 310330.

FONSECA, Maria Cecília Londres.

(1997). 0 patrimônio em processo. Trajetória da política federal de preservação no Brasil. Rio de Janeiro: UFRJ / IPHAN.
GONÇALVES, José Reginaldo Santos.

(1996). A retórica da perda. Os discursos do patrimônio cultural no Brasil. Rio de Janeiro: UFRJ, IPHAN.

(2005). Ipea 40 anos: uma trajetória voltado para o desenvolvimento. Depoimentos ao CPDOC. Rio de Janeiro, FGV/Ipea.

LEAL, Cláudia Feierabend Baeta.

(2012). As missões da Unesco no Brasil: Michel Parent. In: Márcia Chuva; Antonio Gilberto Ramos Nogueira (Orgs.); Patrimônio cultural, políticas e perspectivas de preservação no Brasil. Rio de Janeiro: Mauad X /Faperj. p.133-144.

LONDRES, Maria Cecília Fonseca.

(1997). O patrimônio em processo. Rio de Janeiro, UFRJ/MinC-IPHAN.

MAIA, Tatyana de Amaral.

(2012). Cardeais da cultura nacional: 0 Conselho Federal de Cultura e o papel cívico das políticas culturais na ditadura civil-militar (19671975). São Paulo: Instituto Itaú Cultural/ Iluminuras.

MICELI, Sérgio.

(1984).“0 processo de'construçãoinstitucional' na área cultural federal (Anos 70). In (org.). Estado e Cultura no Brasil. São Paulo, Difel, P. 53-85.

MICELI, Sérgio.

(1984). "Teoria e prática da política cultural oficial no Brasil" In: .(org.). Estado e Cultura no Brasil. São Paulo, Difel, p. 97-112.

M0TTA, Rodrigo Patto Sá.

(2014). As universidades e o regime militar. Rio de Janeiro: Zahar. 
OLIVEIRA, Lúcia Lippi.

(2007). Política Nacional de Cultura: dois momentos em análise - 1975 e 2005. In: Ângela de Castro Gomes (Coord.); Direitos e cidadania: memória, política e cultura. Rio de Janeiro: FGV/FAPERJ/CNPq. p. 137-153.

ORTIZ, Renato.

(1975). Planejamento \& desenvolvimento. N. 1, ano 1, 1973, p.6-21. N. 27, ano 3, p.26-45.

(1985). Estado autoritário \& cultura. In:

Cultura brasileira \& identidade nacional. São

Paulo, Brasiliense, P. 79-126.
RIDENTE, Marcelo.

(2003). Cultura e política: os anos 1960-1970 e sua herança. In: Jorge Ferreira; Lucilia Neves Delgado (Orgs.); O Brasil Republicano 4. Rio de Janeiro, Civilização Brasileira. p. 133-166.

\section{Recebido em}

abril de 2014

Aprovado em

julho de 2014 